\title{
Em busca da liberdade nas universidades: para que serve a pesquisa em educação?'
}

António Nóvoal

\begin{abstract}
Resumo
0 texto, que corresponde à transcrição da palestra proferida no Porto, no Congresso Europeu de Pesquisa Educacional (4 de setembro de 2014), inicia-se com quatro histórias que são sintomas da corrosão atual das universidades e da pesquisa. Depois, na parte central, a partir de três palavras começadas por E e mais uma, criticam-se as ideologias de "modernização" que estão a dominar as universidades: excelência, empreendedorismo, empregabilidade, mais europeização. Na parte final, tiram-se conclusões para a pesquisa educacional, defendendo-se a necessidade de reforçar: a) práticas de debate e culturas de colegialidade; b) lógicas de diversidade e de convergência; c) processos de desenvolvimento de uma educação plena num quadro de abertura e de compromisso social. A primeira e a última palavra deste texto é liberdade, pois, sem ela, não há pensamento, nem ciência, nem educação, isto é, não há universidade.
\end{abstract}

\section{Palavras-chave}

Excelência - Empreendedorismo - Empregabilidade Europeização - Liberdade - Universidades.
I- 0 texto, originalmente publicado no European Educational Research Journal, é traduzido do inglês e corresponde à transcrição da palestra proferida no Porto, no Congresso Europeu de Pesquisa Educacional (4 de Setembro de 2014). Por essa razão, mantém os traços da oralidade.

II- Universidade de Lisboa, Lisboa, Portugal. Contato: anovoa@reitoria.ulisboa.pt 


\title{
What is educational research for?'
}

António Nóvoa"

\begin{abstract}
This text is a transcript of the keynote address delivered in Porto, at the European Conference on Educational Research (4 September 2014). It begins with four stories that are symptoms of the current corrosion of universities and research, which we cannot ignore. Then, in the second section, three words, plus one, are presented to criticize the ideologies of "modernization" that are dominating the university world: excellence, entrepreneurship, employability, and Europeanization. At the end, some conclusions are drawn for educational research, advocating the need to strengthen: (i) dialogical practices and cultures of collegiality; (ii) methods of diversity and convergence; (iii) educational development in a framework of openness and social commitment. The first and the last word of this text is freedom, because without it there is no thought, no knowledge, no education, that is, there is no university.
\end{abstract}

\section{Keywords}

Excellence - Entrepreneurship - Employability Europeanization - Freedom - Universities.

\footnotetext{
I- The text is a transcript of a keynote address. Thus, it has some characteristics of orality (Congresso Europeu de Pesquisa Educacional ( Porto, Portugal, 4 de Setembro de 2014).

II- Universidade de Lisboa, Lisboa, Portugal.

Contact anovoa@reitoria.ulisboa.pt
} 
Depois de sete anos, de grande intensidade, como Reitor da Universidade de Lisboa, passei o último ano no Brasil. Foi uma experiência extraordinária. Pude viver, in loco, a realidade de outro país, de outro continente, e tomar consciência de como são semelhantes as questões que nos afetam, de um e do outro lado do Atlântico, em todos os lugares do mundo.

Ao longo de 2014, durante a preparação desta palestra, apercebi-me melhor da insanidade que está a tomar conta da vida acadêmica. Os sinais não são novos, mas têm vindo a agravar-se ano após ano. 0 nosso mal-estar é grande, mas parecemos resignados e apáticos, como se tudo isto fosse inevitável, como se não houvesse alternativa. Chegou o tempo de dizer "não".

Este ano, celebra-se o centenário da Primeira Grande Guerra (1914-1918). Vale a pena recordar que ela aconteceu, como todas as guerras, não tanto por causa das atitudes bélicas e agressivas de alguns, mas sobretudo por uma espécie de consentimento generalizado de muitos, que acabariam por ser as suas principais vitimas ${ }^{1}$.

"Vemos, ouvimos e lemos. Não podemos ignorar". Esses versos de Sophia de Mello Breyner, cantados durante as lutas pela liberdade em Portugal, explicam a decisão de usar o meu tempo não para uma "palestra convencional" 2 , mas para juntar a minha voz a grupos e movimentos que estão a combater as tendências dominantes no espaço universitário, a combater por novas formas de organização da vida acadêmica.

\section{Vemos, ouvimos e lemos. Não podemos ignorar!}

O que vi, ouvi e li, e não posso ignorar? A lista é longa, mas deixo-vos apenas quatro exemplos, simples, mas esclarecedores.

1- Ver o discurso de Roger Martin du Gard no banquete oficial do Prêmio Nobel, em Estocolmo, no dia 10 de dezembro de 1937.

2- A palestra teve início com a imagem do famoso cachimbo de Magritte, acompanhada pela seguinte frase: "This is not a keynote address".
Primeiro. Vi as notícias sobre o embuste preparado por John Bohannon, que conseguiu publicar diferentes versões de um falso artigo científico em 157 periódicos de livre acesso, alguns da responsabilidade de importantes editoras internacionais como a Wolters Kluwer, a Sage e a Elsevier.

A questão é: Por que é que aceitamos pagar quantias consideráveis para publicar o nosso trabalho num sistema editorial tão medíocre? Por que é que nos resignamos perante essa insanidade? 0 que é que nos está a acontecer?

Segundo. Ouvi o prêmio Nobel Randy Schekman apelar a um boicote a revistas internacionais de referência, como a Nature e a Science, porque, na sua opinião, estão a distorcer o processo científico e a impor uma tirania que deve ser rejeitada.

A questão é: Por que é que não fazemos nada contra esta indústria editorial que está a causar tantos danos à ciência? Por que é que permitimos que as prioridades do nosso trabalho sejam definidas por interesses comerciais e orientações nocivas?

Terceiro. Li a história de Haruko Obokata, a jovem cientista japonesa acusada de falsear imagens numa pesquisa sobre as células-tronco, uma história semelhante a tantas outras dos últimos anos.

A questão é: Por que é que aceitamos as pressões dessa cultura de "publicar ou perecer" 3 ? Por que é que aceitamos o controle das nossas vidas por "fatores de impacto" e um produtivismo cego? Por que é que consentimos? Por que é que nos resignamos?

3 - Em inglês, "publish or perish culture". 
Quarto. Recentemente, vi, ouvi e li as notícias sobre a avaliação do sistema científico português, conduzido através de um acordo entre a Fundação para a Ciência e Tecnologia (Portugal) e a European Science Foundation. 0 acordo previa que apenas metade dos centros de pesquisa deveria ter financiamento ${ }^{4}$. No caso da pesquisa em educação, mais de 70\% dos centros foram eliminados logo na primeira fase. A avaliação foi conduzida da pior maneira possível, por avaliadores estrangeiros, através de métricas absurdas, sem um conhecimento mínimo da realidade do país, sem uma visita aos centros, sem qualquer discussão com os pesquisadores...

A questão é: Por que é que aceitamos participar nesses painéis, usando métodos e cumprindo orientações políticas desse tipo? Por que é que aceitamos colaborar na erosão do nosso próprio campo científico? Por que é que aceitamos o inaceitável? Por quê?

Deixo-vos quatro histórias que tiveram lugar nos últimos meses. Poderia partilhar convosco muitas outras, como, por exemplo, o programa de computador criado por pesquisadores do Massachusetts Institute of Technology que "fabrica" falsos artigos acadêmicos na área da ciência da computação. 0 programa está disponível numa página da internet e, por muito inconcebível que isso nos possa parecer, vários artigos forjados por esse processo foram aceitos para publicação em importantes editoras internacionais, como a Springer, o Institute of Electrical and Electronic Engineers, e muitas outras.

Essas histórias interessam-me não em si mesmas, mas como sinais, como sintomas de um mal-estar mais profundo que afeta a vida acadêmica e universitária. São sinais que têm vindo a multiplicar-se a um ritmo alarmante nos últimos anos, sintomas de uma corrosão

4 - A esse propósito, ver o texto da astrofísica Amaya Moro-Martin (2014). das universidades e da pesquisa, que não podemos ignorar. Por isso, decidi redigir este apelo a favor de uma vida acadêmica diferente, um apelo à nossa responsabilidade individual e coletiva. Chegou o tempo de dizer "não".

Contei-vos quatro histórias - sobre John Bohannon, Randy Schekman, Haruko Obokata e a avaliação da pesquisa em Portugal - e coloquei quatro perguntas que, na verdade, são apenas uma: por que é que aceitamos? Por que é que consentimos? Por que é que colaboramos? Por quê?

Claro que as perguntas são retóricas. Todos sabemos a resposta: trata-se de uma luta pela sobrevivência na selva acadêmica. Mas precisamos problematizá-la, refletir sobre ela no contexto das tendências dominantes no espaço universitário, em todo o mundo, mas sobretudo na Europa depois do Processo de Bolonha.

Talvez essas tendências possam ser resumidas através da comparação entre duas ideias bem conhecidas. A primeira pertence a Eliot Freidson (1986, p. 436): “As universidades são invenções sociais notáveis para apoiar o trabalho que não tem valor comercial imediato". A segunda é de Nicholas Barr, economista que desempenhou um papel importante nas reformas do ensino superior no Reino Unido: há 50 anos, o ensino superior não tinha grande relevância em termos econômicos; nos dias de hoje, é necessário compreender o valor econômico das universidades $(2012)^{5}$.

Essas ideias estão separadas por cerca de três décadas, mas entre uma e outra vai uma distância de grande significado naquilo que se espera das universidades. Já não se trata de sublinhar a importância do conhecimento para o desenvolvimento econômico e social. 0 que conta, agora, é o próprio valor econômico das universidades.

Num raciocínio excessivamente breve, e até simplista, talvez seja possível ilustrar essa ideologia com três $E$ e mais um. Esses $E$ são conceitos tóxicos, porque a nossa

5- Ver também a página de Nicholas Barr na internet: http://econ.Ise. ac.uk/staff/nb. 
sobrevivência imediata depende da capacidade para respirarmos nesse ambiente nocivo, ainda que tal nos condene a uma morte lenta.

As palavras não são culpadas. 0 problema não está nas palavras, mas sim nas ideologias de "modernização" que olham sobretudo para o "valor econômico das universidades".

\section{Ideologias de "modernização"? Três E e mais um}

\section{$E$ de excelência}

Excelência é um dos conceitos mais recorrentes no mundo universitário, sobretudo quando se trata de definir os planos estratégicos das instituições e, em particular, de alimentar a esperança de ser uma "universidade de pesquisa de nível mundial" ". Como é óbvio, ninguém pode ser contra a excelência. Mas, por trás desse conceito, está a tendência para um produtivismo que enfraquece as bases da profissão acadêmica.

Publicar ou perecer? Essa cultura está diretamente relacionada com modalidades de avaliação dos professores e de produção de rankings que dominam as universidades, dando um enorme poder às grandes companhias editoras internacionais.

"Quem são os capitalistas mais implacáveis no mundo ocidental?" - pergunta George Monbiot, escritor e jornalista inglês:

Quem é responsável por práticas monopolistas que fazem Walmart parecer uma pequena loja de esquina e Rupert Murdoch um socialista? Há muitos candidatos, mas o meu voto não vai nem para os bancos, nem para as petrolíferas, nem para as companhias de seguros, mas - vejam bem - para as editoras acadêmicas (MONBIOT, 2011).

6- Em inglês, world-class research university. Ver, a esse propósito, Robertson (2012).
Trabalhamos todos, gratuitamente, para as revistas e editoras acadêmicas, como autores ou como revisores de artigos científicos, e, no entanto, somos obrigados a pagar verbas escandalosas para ter acesso a essas publicações, que foram financiadas, principalmente, por fundos públicos (NORA, 2014). Alguma coisa está errada.

Mesmo uma das universidades mais ricas do mundo, a Universidade de Harvard, aprovou uma declaração, há dois anos, informando que não tinha dinheiro para pagar os preços elevados pedidos pelas revistas científicas (HARVARD UNIVERSITY, 2012). E, nesse mesmo ano, 2012, o matemático Tim Gowers, galardoado com a medalha Fields, lançou um movimento contra o exorbitante "custo do conhecimento", apelando a um boicote às revistas da responsabilidade da Elsevier e à adoção de formas alternativas de publicação acadêmica (THE COST OF KNOWLEDGE, 2012).

Estamos perante a indução de um produtivismo que conduz à banalização de práticas inaceitáveis, como o autoplágio, a autocitação ou o "fatiamento" de artigos. Há mesmo quem se orgulhe de ter publicado centenas e centenas de artigos ao longo da sua vida acadêmica. Será isso uma coroa de glória ou de demência?

Cada dia se publica mais. Cada dia se lê menos. Há pressões cada vez maiores para impor uma cultura de produtivismo. Não podemos ser cúmplices dessa corrupção da ciência e das universidades que está a destruir a vida acadêmica. É tempo de dizer "não".

\section{$E$ de empreendedorismo}

0 que quero criticar nessa palavra?

Por um lado, quero criticar a "universidade empreendedora”, a emergência de práticas de gestão que olham para as universidades como se fossem empresas. Permitam-me que mencione o Manifesto for universities that live up to their missions, lançado em 2012, no qual se denunciam as tendências dominantes 
de governo das universidades, construídas em torno de ideias como eficiência, rentabilidade e competitividade, ideias que estão a arruinar a liberdade acadêmica.

Um dos nossos maiores problemas é a separação, cada vez mais profunda, entre a gestão e a vida acadêmica. Dentro das universidades, o poder tem vindo a passar dos acadêmicos para os gestores e burocratas.

Por outro lado, quero falar do empreendedorismo enquanto atitude caracterizada pela inovação e pelo risco. Ninguém pode ser contra. Infelizmente, essa tendência está a conduzir a ritmos de trabalho cada vez mais acelerados e à adoção de dispositivos de avaliação que deixam na sombra muitos outros aspectos do trabalho acadêmico.

Essa situação é denunciada pelos subscritores do Slow Science Manifesto, documento de 2010 em que se pode ler: "A ciência necessita de tempo para pensar, de tempo para ler e de tempo para falhar. A ciência nem sempre sabe o que está certo num determinado momento". 0 manifesto conclui com um último pedido, dirigido ao público: "Fiquem conosco, apoiem-nos, enquanto pensamos" .

Talvez a melhor maneira de contrariar essas concepções, erradas, de empreendedorismo seja através do recurso à palavra francesa désintéréssement, tão difícil de traduzir para outras línguas. Não significa desinteresse, mas sim um interesse maior, mais elevado, bem definido por Jacques Derrida (2011), na sua obra L'université sans condition, isto é, a universidade sem condição, de uma liberdade incondicional ${ }^{8}$.

0 movimento a favor de uma "ciência lenta” é parte de uma ação mais vasta contra as tendências empreendedoras, no sentido negativo do termo, que estão a destruir o tecido universitário. É tempo de dizer "não".

\footnotetext{
7- The Slow Science Manifesto pode ser consultado na página da internet http://slow-science.org/

$\mathbf{8}$ - Ver também Holmwood (2011).
}

\section{$E$ de empregabilidade}

0 conceito de empregabilidade é o mais recorrente e tóxico nos debates europeus, sempre seguido por um outro conceito, ainda mais tóxico: “educação e formação ao longo da vida" . Durante o século XX, o direito à educação fez parte de grandes lutas e movimentos sociais. Agora, com a repetição sistemática do princípio da "educação e formação ao longo da vida”, a educação deixou de ser um direito e transformou-se num dever: cada um tem a obrigação de se educar ao longo da vida no sentido de melhorar os seus níveis de empregabilidade.

As universidades foram incorporando a ideia de empregabilidade, abdicando de grande parte das suas missões educacionais e culturais, para se focarem, primordialmente, na preparação para os empregos ou, melhor dizendo, para futuros empregos.

A aceitação acrítica dessas tendências torna-nos responsáveis pela nossa própria destruição, como se explica num importante documento, Charte de la désexcellence (2014), recentemente publicado por um grupo de acadêmicos europeus. As nossas atitudes, muitas vezes por omissão ou consentimento, abrem caminho à adoção e desenvolvimento de ideologias que estão a condicionar seriamente as universidades, a criar importantes constrangimentos à vida acadêmica e a redefinir erradamente as prioridades da investigação. É tempo de dizer "não".

Intencionalmente, decidi descrever os três $E$ confrontando-os sempre com movimentos e formas de resistência que têm vindo a ganhar cada vez mais importância no interior do mundo universitário: a declaração da Universidade de Harvard, o boicote proposto por Tim Gowers, o Manifesto for universities that live up to their missions, o Slow Science Manifesto, a Charte de la désexcellence... ${ }^{10} \mathrm{E}$ a

\footnotetext{
9- Em inglês, lifelong learning.

10 - Ver também uma petição recente de pesquisadores europeus, They have chosen ignorance!.
} 
minha maneira de chamar a atenção para a nossa própria responsabilidade, como professores, como pesquisadores, como educadores e como membros de sociedades científicas na área da educação.

No princípio, disse-vos que apresentaria três $E$ e mais um.

\section{0 meu último $E$ refere-se à europeização}

Estamos perante mais um conceito tóxico. Depois de décadas de europeização, a Europa está como está. Não falarei sobre isso. Mas quero expor as divisões entre norte e sul, entre centro e periferia, que as políticas da União Europeia no campo da ciência e inovação estão a agravar.

Habitualmente, sublinha-se a importância do conhecimento para a organização e progresso das sociedades contemporâneas. É esse o argumento principal para aumentar as verbas europeias para a ciência. 0 programa Horizonte 2020 está, hoje, dotado com um orçamento de 79 mil milhões de euros.

Curiosamente, ninguém põe em causa a estratégia de "fundos competitivos" que regula as políticas europeias de distribuição de recursos na área da ciência. É o melhor exemplo da ideologia dos três $E$. 0 resultado é óbvio: os fortes ficam mais fortes; os frágeis, mais frágeis.

Depois de quase três décadas na União Europeia, Portugal continua a ser um contribuinte líquido ${ }^{11}$ para os fundos europeus de ciência. Ironicamente, poder-se-ia argumentar que os cidadãos dos países menos desenvolvidos estão a pagar a ciência que se faz nos países mais desenvolvidos. Que estranha europeização.

E depois somos confrontados com histórias, como aquela que vos contei anteriormente, sobre a avaliação dos centros de pesquisa em Portugal. 0 trabalho é realizado sob os auspícios da European Science Foundation, com a cumplicidade de

11- Contribuinte líquido significa que Portugal contribui com mais verbas para o orçamento europeu nesse setor do que aquelas que recebe da União Europeia. alguns dos nossos colegas. É desnecessário dizer que tudo é feito de acordo com os melhores "padrões internacionais", legitimados com linguagens e métricas de excelência, inovação e competitividade, empreendedorismo, transferência de conhecimento e mérito tecnológico, outputs, produtividade e impacto. Mas o problema está precisamente aqui. Em nome da europeização, reproduzem-se as mesmas fraturas de sempre. É tempo de dizer "não".

Quatro vezes “não”. À excelência. Ao empreendedorismo. À empregabilidade. A "esta" europeização. Não por causa das palavras, mas por causa das ideologias que elas carregam.

Deixem-me ser totalmente claro. Não alimento nenhuma nostalgia acadêmica. Mas isso não me obriga a aderir a ideologias de "modernização" que estão a destruir a nossa vida acadêmica e a nossa liberdade intelectual. Essas ideologias estão a empobrecer o trabalho científico, em particular no campo da pesquisa em educação. É o que tentarei explicar na última parte desta palestra.

\section{E a propósito da pesquisa em educação?}

Deixar-vos-ei, de novo, três ideias, e mais uma.

\section{Em vez de "excelência", precisamos de debate e cultura}

Em vez da ideologia da "excelência", devemos basear a pesquisa em educação no debate e na cultura. Um entendimento errado do conceito de excelência conduz a separar os melhores dos outros, esquecendo que, nas sociedade do século XXI, é central que todos tenham acesso ao conhecimento e que haja uma valorização não apenas da ciência mas também da cultura científica.

0 debate, o seminário e as comunidades de diálogo são elementos fundamentais da universidade. Essa tradição tem sido posta em 
causa por um sistema de revisão pelos pares ${ }^{12}$ cada vez mais desacreditado, por avaliações puramente quantitativas ou bibliométricas $\mathrm{e}$ por tendências que medem fatores de impacto duvidosamente definidos.

É necessário reconstruir uma cultura de debate e de crítica, marcada pela interação, pelo diálogo, pela leitura conjunta dos nossos trabalhos, pela capacidade de nos envolvermos numa conversa intelectual com os outros. Não podemos nos resignar perante a tirania dos números, perante dispositivos quantitativos de avaliação que estão a pôr em causa a criatividade e a liberdade. Precisamos reinventar a pesquisa como uma práxis coletiva aberta e colaborativa.

Para transformar as universidades, é necessário haver confiança em nós e nos outros, "dentro" (nas instituições) e "fora" (na sociedade). Sem confiança, a tendência dominante será sempre reproduzir lógicas burocráticas e métricas quantitativas, empurrando a vida acadêmica para um produtivismo tantas vezes sem sentido. Tudo precisa de tempo, colaboração e compromisso, colegialidade e liberdade.

\section{Em vez de "empreendedorismo", precisamos de diversidade e convergência}

A ideologia do empreendedorismo tende a reduzir a pesquisa a desenvolvimentos tecnológicos ou a exercícios aplicados. Um certo estreitamento tem, por vezes, o efeito de voltar o trabalho científico para dentro do próprio campo educativo. Ora, a história educacional mais inspiradora baseia-se no contrário, numa diversidade de abordagens, de metodologias e de maneiras de pensar.

É estranho que, neste início do século XXI, quando as correntes científicas mais inovadoras procuram dinâmicas de convergência e de fertilização mútua, alguns pesquisadores estejam preocupados sobretudo com as questões da

\footnotetext{
12- Em inglês, peer-review system.
}

identidade e da "disciplinarização" das ciências da educação.

Pessoalmente, acredito que precisamos alargar o espectro do nosso trabalho, numa perspectiva muito próxima da que é defendida por Michel Serres:

Dedicados à procura da verdade, nem sempre a atingimos quando a buscamos por análises e equações, por experiências ou evidências formais; por vezes, é preciso recorrer ao ensaio; e quando o ensaio não chega, sigamos pelo conto, se for possível; se a meditação fracassa por que não tentar a narrativa? (1991, p. 249).

A questão central é como enriquecer, aprofundar e diversificar a nossa compreensão dos temas educacionais. Não há um caminho único e, certamente, não podemos esperar que se obtenha um consenso na forma de organizar e de orientar o campo científico em educação. Mas podemos trabalhar para que a pesquisa acolha a diversidade e procure a convergência. Não nos podemos fechar no interior de uma "disciplina” única. Precisamos trabalhar nas fronteiras de vários conhecimentos, juntar perspectivas diferentes na compreensão dos fenômenos educativos.

\section{Em vez de "empregabilidade", precisamos de plenitude e abertura}

Vale a pena recordar a ironia de David Labaree, numa palestra dirigida a jovens pesquisadores em educação: "Errem, sejam preguiçosos e irrelevantes; e pensem no vosso trabalho como um esforço para equilibrar os valores da verdade, da justiça e da beleza" (2012, p. 74). Esses conselhos não podem ser interpretados literalmente, mas sim como uma crítica às tendências utilitaristas que dominam as universidades.

A pesquisa deve ser capaz de reforçar uma educação superior ampla, que não se esgota na "empregabilidade". Para isso, importa 
consolidar os laços entre a educação e a ciência, entre a formação e a pesquisa, enriquecendo a vida universitária num duplo sentido: por um lado, construindo uma educação de base, que dê a cada um os instrumentos de conhecimento e de autoconhecimento, de desenvolvimento de uma vida plena também na relação com o trabalho; por outro lado, realizando um esforço para levar a pesquisa até um público mais alargado, de modo a ligar a reflexão científica aos debates públicos sobre educação.

Todos sabemos que a educação está saturada de opiniões e de certezas e, por isso, é tão difícil instaurar e legitimar um conhecimento especializado nesse campo. Mas essa dificuldade é, ao mesmo tempo, uma das nossas principais vantagens, pois torna mais fácil uma relação próxima entre a ciência e a sociedade, uma abertura decisiva para as sociedades do século XXI.

Aqui ficam as minhas três respostas à questão Para que serve a pesquisa em educação? Mas prometi-vos três respostas, e mais uma. A minha última resposta diz respeito à Europa. Se acreditamos, como gostamos de dizer, que a educação e o conhecimento são elementos centrais para o desenvolvimento dos países, então temos de repensar a forma como os fundos europeus de ciência estão a ser distribuídos. Não podemos aceitar acriticamente o argumento de que os fundos estão a ser concedidos apenas de acordo com a qualidade e o mérito das equipes de investigação, das infraestruturas e das projetos apresentados. $\mathrm{Na}$ verdade, essa política reproduz, cinicamente, as desigualdades de partida. Por essa via, nunca nos tornaremos mais iguais no espaço europeu.

A retórica da europeização tem estado ao serviço de divisões e fraturas cada vez mais profundas. Nenhum de nós pode continuar a jogar esse jogo, ingenuamente, como se nele não tivéssemos qualquer responsabilidade. Chegou o tempo de agir, dentro de cada uma das nossas universidades, mas também em associações como a European Educational Research Association.

Está na altura de concluir esta viagem recordem-se que isto não é uma "palestra convencional” - por temas universitários, pela vida acadêmica e pela pesquisa educacional. Espero ter sido capaz de juntar pontos de vista muito distintos, no esforço para revelar dilemas e problemas que nos afetam a todos.

Comecei com uma poeta do Porto, Sophia de Mello Breyner. Permitam-me que termine com um escritor de Lisboa, Vergílio Ferreira: "Não se pode pensar fora das possibilidades da língua em que se pensa" (1992, p. 9). Do mesmo modo, também não se pode conhecer fora das possibilidades da ciência em que se conhece. É por isso que precisamos alargar o repertório da nossa ciência, dos pontos de vista teórico e metodológico. Alargar o espectro das nossas maneiras de pensar e de falar sobre educação. Aprofundar o nosso compromisso com a inclusão, a educação e a cultura. É para isso que serve a pesquisa educacional.

Todas as minhas palavras podem ser resumidas numa só - liberdade. As formas dominantes de organização do trabalho acadêmico e de avaliação dos professores estão a afetar gravemente a ideia de universidade e as nossas vidas profissionais e pessoais. Chegou o tempo de repensar a pesquisa educacional numa perspectiva mais ampla, com uma liberdade sem condição. Porque a liberdade é tudo, e todo o resto é nada. 


\section{Referências}

BARR, Nicholas. The higher education white paper: the good, the bad, the unspeakable - and the next white paper. Social Policy and Administration, v. 46, n. 5, p. 438-508, 2012.

CHARTE DE LA DÉSEXCELLENCE. Versão de Janeiro de 2014. Disponível em: <http://lac.ulb.ac.be/LAC/charte_files/Charte_ Desexcellence_1-1.pdf>.

DERRIDA, Jacques. L’université sans condition. Paris: Galilée, 2001.

DU GARD, Roger Martin. Banquet speech. Nobelprize.org. Nobel Media AB 2014. Disponível em: <http://www.nobelprize.org/ nobel_prizes/literature/laureates/1937/gard-speech.html>.

FERREIRA, Vergílio, Pensar. Lisboa: Bertrand, 1992. p. 9.

FREIDSON, Eliot. Les professions artistiques comme défi à l'analyse sociologique. Revue Française de Sociologie, v. 27, n. 3, p. 436, 1986.

HARVARD UNIVERSITY, Faculty Advisory Council Memorandum on Journal Pricing, 17 de Abril de 2012. Disponível em: $<$ http://isites.harvard.edu/icb/icb.do?keyword=k77982\&tabgroupid=icb.tabgroup14344>.

HOLMWOOD, John (Ed.). A manifesto for the public university. London: Bloomsbury, 2011.

LABAREE, David. A sermon on educational research. International Journal for the Historiography of Education, v. 2, n.1, p. $74,2012$.

MANIFESTO FOR UNIVERSITIES THAT LIVE UP TO THEIR MISSIONS. Disponivel em: <http://www.univendebat.eu/manifeste/ manifesto-for-universities-to-stand-up-for-their-missions > .

MONBITO, George. Academic publishers make Murdoch look like a socialist. The Guardian, 29 ago. 2011.

MORO-MARTIN, Amaya. A call to those who care about Europe's sicence. Nature, v. 514, n. 7521, 8 out. 2014.

NORA, Dominique. Recherche publique, profits privés. Le Nouvel Observateur, n. 2583, p. 52-53, 8 maio 2014.

ROBERTSON, Susan L. World-class higher education (for whom?). Prospects, v. 42, p. 237-245, 2012.

SERRES, Michel. Le tiers-instruit. Paris: Éditions François Bourin, 1991. p. 249.

THE COST OF KNOWLEDGE. Disponível em: <http://gowers.files.wordpress.com/2012/02/ elsevierstatementfinal.pdf>.

THEY HAVE CHOSEN IGNORANCE! Disponível em: <http://openletter.euroscience.org/open-letter/>.

António Nóvoa é reitor da Universidade de Lisboa (2006-2013). 